\title{
Elección de Escuela, Movilidad y Segregación Escolar del Alumnado Vulnerable en Barcelona
}

\author{
School Choice, Mobility and School Segregation of Vulnerable \\ Students in Barcelona
}

\author{
Xavier Bonal $1 *$ \\ Adrián Zancajo ${ }^{2}$ \\ ${ }^{1}$ Universitat Autònoma de Barcelona, España \\ ${ }^{2}$ University of Glasgow, Reino Unido
}

\begin{abstract}
Este artículo analiza la relación entre elección de escuela, movilidad y segregación escolar del alumnado socialmente desfavorecido en Barcelona. Las particularidades del modelo de zonificación escolar de la ciudad, basado en un complejo sistema de elección restringida pero que otorga un amplio número de opciones de proximidad, lo convierten en un caso único en el que observar la relaciones entre movilidad y desigualdades educativas. A partir de datos de residencia y escolarización del alumnado de educación infantil y primaria el trabajo nos muestra cómo la interacción entre segregación residencial y pautas de movilidad del alumnado es generadora de mayor segregación escolar del alumnado vulnerable, tanto de nivel socioeconómico bajo como de nacionalidad extranjera. Un análisis contrafactual que simula modelos de escolarización basados en mayor proximidad demuestra que la segregación escolar del alumnado vulnerable se reduciría hasta un 50\% en escenarios de menor movilidad y mayor escolarización de proximidad. Asimismo, estos escenarios reducirían la desigualdad de escolarización entre escuelas públicas y concertadas. El artículo concluye con una reflexión sobre las implicaciones políticas del análisis.
\end{abstract}

Descriptores: Elección escolar; Segregación escolar; Movilidad; Barcelona; Desigualdad educativa.

\begin{abstract}
This article analyzes the relationship between school choice, mobility and school segregation of socially disadvantaged students in Barcelona. The particularities of the city's zoning system and catchment areas, based on a complex model of restricted choice with a wide number of proximity options, make it a unique case to observe the relationship between mobility and educational inequalities. By using data on students' residence and schooling of children in pre-school and primary education, the article shows how the interaction between residential segregation and patterns of student mobility generates greater school segregation of both students from low socioeconomic status and foreign students. A counterfactual analysis that simulates schooling models based on greater proximity shows that the school segregation of vulnerable students would be reduced by up to $50 \%$ in scenarios of less mobility and greater proximity schooling. Likewise, these scenarios would reduce the inequality of schooling between public and private schools. The article concludes with some reflections on the political implications of the analysis.
\end{abstract}

Keywords: School choice; School segregation; Mobility; Barcelona; Education inequalities.

*Contacto: xavier.bonal@uab.cat

Recibido: $\quad 20$ de marzo 2020

$1^{\text {a }}$ Evaluación: 13 de junio 2020

ISSN: $1696-4713$

$2^{\text {a }}$ Evaluación: 9 de julio 2020

www.rinace.net/reice/

Aceptado: 30 de agosto 2020

revistas.uam.es/reice 


\section{Revisión de la literatura}

Los debates sobre las virtudes y los defectos de la elección de escuela enfrentan a menudo distintas posiciones políticas en educación. En los últimos años, además, estos debates han ganado protagonismo en la medida en que numerosos países han llevado a cabo reformas educativas que han aumentado las posibilidades de elección de escuela. La expansión de los sistemas de cheque escolar (voucher), el aumento de la financiación pública a las escuelas privadas, el crecimiento de las escuelas charter o la mayor capacidad otorgada a las escuelas para decidir sobre los criterios de admisión son reformas con orientación de mercado que, en las últimas décadas, se han desarrollado en diversos países (OCDE, 2017). Como resultado de estas políticas y otras tendencias, en los últimos 25 años, la mayoría de los sistemas educativos de la OCDE han aumentado las oportunidades de elección de escuela (Musset, 2012) y con ello la preocupación por los posibles efectos de una mayor capacidad de elección sobre la calidad y la equidad de los sistemas educativos.

Los defensores de la elección escolar sostienen que conlleva mejoras sustantivas en la calidad y la equidad de los sistemas educativos (Chubb y Moe, 1990; Hoxby, 2003). Las mejoras en la calidad se derivan, principalmente, de la capacidad de estas políticas para promover una mayor competencia entre las escuelas. Dado que la capacidad de elección de escuela otorga poder de decisión a la demanda (los usuarios tienen capacidad de cambiar de centro), las escuelas se ven obligadas a competir para atraer y retener a los usuarios. Esta competencia, de este modo, genera incentivos para mejorar la calidad académica de la oferta escolar. Los beneficios sobre la equidad educativa están asociados a la reducción de los efectos de la segregación residencial sobre la segregación escolar. Según esta aproximación, la elección de escuela abre la posibilidad de que familias pobres, especialmente aquellas altamente motivadas, "escapen" de las escuelas de su entorno social inmediato, que suelen ser de baja calidad, y consigan acceder a mejores escuelas. Los mecanismos de distribución de recursos que refuercen la capacidad de elección de escuela, mediante vouchers universales o selectivos, por ejemplo, se consideran en definitiva buenos dispositivos para aumentar la calidad y la igualdad de oportunidades de los sistemas educativos (Chubb y Moe 1990; Hoxby 1998; Lindbom, 2010; Merrifield 2001).

Por su parte, otros autores se muestran especialmente críticos con la elección de la escuela. Sus análisis resaltan los efectos negativos producidos por las políticas que promueven mayores niveles elección, porque incentivan sistemas de selección del alumnado por parte de las escuelas para mejorar su reputación académica y su capacidad de atracción (Ball, 1998; van Zanten, 1996; West, Hind y Pennell, 2004). Asimismo, estos estudios destacan el hecho de que las familias de bajo nivel socioeconómico tienen menos posibilidades de acceder a las "mejores" escuelas, ya sea por razones financieras (cuando se permiten aportaciones económicas complementarias) o debido a asimetrías de información (Allen, 2007; Elacqua, Montt y Santos, 2013; Gewirtz, Ball y Bowe, 1995; van Zanten, 1996). En parte, estos fenómenos explican por qué las políticas que amplían la elección escolar no necesariamente reducen la segregación escolar, sino que pueden incluso aumentar la estratificación social entre centros educativos. En muchos de estos estudios se constata que políticas orientadas a aumentar la capacidad de elección facilitan los procesos de huida (white flight) de las clases medias de las escuelas locales, aumentando la concentración y el aislamiento de los estudiantes más vulnerables (Boterman, 2013; Butler y Robson, 2003; Kye, 2018). 
Si bien las revisiones sobre los efectos de la elección escolar y los mercados educativos sobre la equidad educativa subrayan el predominio de los efectos negativos (Musset, 2012; OCDE, 2019; Waslander, Pater y van der Weide, 2010), la relación entre elección y segregación está lejos de ser homogénea y varía entre los diferentes sistemas educativos y territorios. La configuración de los mercados locales de educación o "mercados vividos" (Felouzis, Maroy y van Zanten, 2013; Taylor, 2001) es crucial para comprender la dinámica de la segregación escolar y la posición jerárquica de las escuelas. Factores como el diseño de las políticas de admisión (Bonal y Zancajo, 2019; Dupriez, Barbana y Verhoven, 2018), las características y el tamaño de las zonas educativas (catchment areas) (Boterman et al., 2019), el mayor o menor peso de los proveedores privados sobre el conjunto de la oferta (Alegre y Ferrer, 2010), o diferentes racionalidades de demanda educativa (Ben Porath, 2009; Bonal y Zancajo, 2018a) son algunas de las razones que explican las diferentes interacciones entre la elección escolar, la movilidad y la segregación escolar.

Este artículo se ocupa de analizar la relación entre elección de escuela, movilidad y segregación escolar en un mercado educativo local, en este caso la ciudad de Barcelona. Las particularidades del modelo de zonificación escolar de la ciudad, con un complejo sistema de elección restringida pero que otorga un amplio número de opciones de proximidad, hacen que sea especialmente interesante observar las dinámicas de escolarización en las distintas zonas de la ciudad. El artículo nos mostrará cómo los márgenes amplios de elección escolar no facilitan una escolarización más equitativa, sino que son generadoras de desigualdades en la movilidad del alumnado y, por tanto, de mayor segregación escolar del alumnado, tanto del alumnado extranjero como del alumnado de nivel socioeconómico bajo en prácticamente todas las zonas de la ciudad.

El trabajo se estructura del siguiente modo. En la sección que sigue a esta introducción revisamos la evidencia internacional aportada por los estudios que relacionan segregación escolar y elección de centro. En la siguiente describimos brevemente las particularidades del sistema de admisión escolar de Barcelona, y en especial el sistema de determinación de la proximidad. En la cuarta sección ofrecemos algunos datos de los desequilibrios territoriales más destacados por lo que respecta a la escolarización en la enseñanza obligatoria y mostramos las diferencias entre segregación residencial y segregación escolar. En la siguiente presentamos datos sobre movilidad educativa que permiten entender la polarización territorial en el proceso de escolarización. Este análisis precede a un análisis contrafactual que compara la escolarización real con la que se derivaría de simular la escolarización exclusivamente dentro de la zona educativa o en el centro geográficamente más cercano al domicilio del alumnado. Este análisis revela el impacto del sistema de elección en la segregación escolar del alumnado extranjero o de bajo nivel socioeconómico. El artículo concluye con una reflexión acerca de las implicaciones políticas de este análisis.

\subsection{Elección escolar y segregación}

Las políticas de elección de escuela están destinadas a abrir posibilidades de acceso a escuelas más allá del área de residencia de los estudiantes. Se conciben como programas que brindan mayores oportunidades a todas las familias y, en muchas ocasiones, también se planifican como una estrategia que potencialmente puede reducir los efectos de la segregación residencial sobre la segregación escolar del alumnado socialmente más vulnerable. Varios estudios han evaluado el impacto de las políticas que han ampliado las 
oportunidades de elección de escuela en la segregación escolar comparando la composición de las escuelas según grupo étnico, nivel socioeconómico u otros indicadores antes y después de la implementación de reformas. Frankenberg y otros (2011), por ejemplo, evaluaron el efecto de la expansión de las de las escuelas charter sobre la composición escolar en 40 estados y otras áreas metropolitanas de Estados Unidos. Su estudio reveló que la expansión de estas escuelas aisló a los estudiantes de color y de grupos socioeconómicos más bajos en niveles significativamente más altos que las escuelas públicas tradicionales, un resultado que confirmó los hallazgos de estudios previos (Cobb y Glass, 2003; García, 2008). En un estudio longitudinal que evalúa la segregación entre escuelas en Inglaterra entre 1989 y 2014, Gorard y Siddiqui (2016) identifican la expansión de las grammar schools (escuelas selectivas por criterios académicos) como el factor principal que explica la creciente segregación escolar en el país. Por su parte, Brandén y Bygren (2018) evaluaron los efectos de la introducción del sistema de cheque escolar y el surgimiento de escuelas independientes en Suecia comparando la evolución de 13 cohortes de estudiantes. Su análisis concluye que las mayores oportunidades de elección conducen a una mayor segregación escolar entre estudiantes nativos y no nativos. También para el caso de Suecia, Söderström y Uusitalo (2016) hallaron resultados similares al comparar la segregación escolar académica, socioeconómica y étnica entre municipios que suprimieron los criterios de proximidad en la política de admisión escolar y aquellos municipios que no introdujeron la reforma. En Chile, la evidencia ha demostrado que la implementación del voucher universal aumentó la estratificación social y socioeconómica de las escuelas, no solo entre las escuelas públicas y privadas, sino también dentro de la red de escuelas privadas financiadas con fondos públicos (Elacqua, 2012; Hsieh y Urquiola, 2006).

Más allá de las evaluaciones de impacto, un método alternativo para evaluar los efectos de la elección de escuela en la estratificación escolar consiste en comparar escenarios observados y contrafactuales. Todos los estudios disponibles que han utilizado esta aproximación metodológica destacan, sin excepción, niveles más altos de segregación escolar en escenarios reales en comparación con simulaciones que asignan escuelas a los estudiantes usando diferentes criterios de proximidad geográfica. En Estados Unidos, Sohoni y Saporito (2006) analizan la segregación racial en 22 distritos escolares en escuelas de enseñanza primaria, intermedia (middle schools) y secundaria. Los autores comparan el porcentaje de estudiantes blancos matriculados en escuelas públicas con los residentes en el área de influencia de cada escuela. El estudio muestra cómo el porcentaje promedio de estudiantes blancos matriculados en las escuelas es menor que su presencia en el área de influencia. Esta diferencia es mayor en áreas que tienen proporciones similares de estudiantes blancos y no blancos, lo que significa que cuanto mayor es la heterogeneidad del área de influencia, mayor es la probabilidad de que los estudiantes blancos no opten por la escolarización de proximidad. Los autores también encuentran niveles más altos de segregación escolar en aquellas áreas con mayor presencia de escuelas privadas, magnet y charter, lo que muestra un efecto negativo de los márgenes amplios de elección en la segregación escolar especialmente en contextos con una elevada presencia de alternativas de escolarización privadas. Bifulco, Ladd y Ross (2009) utilizan una metodología similar para el caso de Durham (Carolina del Norte), y también muestran que las escuelas están más segregadas entre grupos étnicos y clases sociales de lo que lo estarían si todos los estudiantes asistieran a las escuelas más cercanas geográficamente. Según los autores, los programas de elección de escuela favorecen que parte de la 
población pueda evitar a determinados grupos sociales (white flight), así como el etnocentrismo neutral (la búsqueda de entornos educativos y sociales similares). Estos efectos son mayores que los que resultan de la posibilidad de que las familias vulnerables puedan escolarizarse fuera de su área de residencia (Archbald, 2003). En otras palabras, el efecto de salida es superior a los movimientos integradores que realizan las familias socialmente menos favorecidas al escolarizarse con estudiantes más favorecidos como producto de las políticas de elección de escuela. El resultado agregado es un aumento de la segregación racial y de clase social.

Allen (2007) muestra cómo la política de elección de escuela secundaria en Inglaterra ha producido un sistema educativo académica y socialmente más estratificado. Compara escenarios observados y contrafactuales en todas las Autoridades Locales de Educación (LEA, por sus siglas en inglés) del país. La autora demuestra que la movilidad de los alumnos en cada LEA depende de la capacidad de los padres de acceder a una escuela que no sea de proximidad. La movilidad es superior según la densidad de población, los indicadores de bienestar social o la presencia de grammar schools (que disponen de autonomía para decidir el número de plazas que ofrecen). Al realizar la asignación simulada de estudiantes en función de la proximidad y los lugares disponibles, Allen concluye que en el escenario contrafactual se reduce significativamente la segregación escolar por nivel académico y por clase social. Burgess y otros (2007) hallan resultados similares al comparar las posibilidades de elección de diferentes familias en su área de proximidad. Su análisis muestra que la segregación escolar es considerablemente más alta que la segregación residencial en aquellas áreas geográficas con mayores posibilidades de elección de escuela.

Resultados similares son observables en análisis para los casos de Alemania (Riedel et al., 2010), Suecia (Östh, Andersson y Malmberg, 2013) o Chile (Santos y Elacqua, 2016). En todos estos casos las reformas educativas que han favorecido las lógicas de mercado y la elección de escuela aumentan notablemente los procesos de segregación escolar, situándola significativamente por encima de la segregación residencial.

\subsection{El sistema de admisión escolar en Barcelona}

Como en el resto de España, en la ciudad de Barcelona las familias mayoritariamente solicitan plaza en educación preescolar en el mismo año en que el niño o la niña cumplen los tres años de edad. Las familias pueden expresar sus preferencias escolares por cualquier escuela pública o privada concertada de la ciudad, y los estudiantes son asignados siguiendo un mecanismo de Boston ${ }^{1}$. En casos de exceso de demanda, las solicitudes se priorizan utilizando tres criterios principales que ya se establecieron en la Ley Orgánica 8/1985 del Derecho a la Educación (LODE). Estos criterios incluyen la proximidad residencial, la inscripción de hermanos en la escuela y los ingresos del hogar.

La particularidad de Barcelona radica en la forma en que se determina la prioridad por proximidad residencial. Existen 29 áreas de influencia o zonas escolares en la ciudad. Todos los residentes en cada zona tienen prioridad por proximidad para acceder a todas

1 El "mecanismo de Boston" es un procedimiento de asignación de estudiantes mediante un algoritmo que maximiza las preferencias del alumnado (familias) a partir de un sistema de baremos basado en criterios pre-especificados. El mecanismo asigna las plazas teniendo en cuenta las plazas disponibles y las preferencias de las familias, que son prioritarias respecto a la puntuación obtenida. 
las escuelas públicas y concertadas dentro del área de influencia. En 2006, el Consorci d'Educació de Barcelona (CEB), organismo público a cargo de la planificación y gestión educativa de la ciudad, estableció un sistema específico de elección. De este modo, se otorgó una capacidad mínima de elección común para equilibrar las oportunidades de elección entre todas las familias. Si bien cada familia puede elegir todas las escuelas ubicadas dentro del área de influencia, el sistema garantizó un mínimo de seis escuelas geográficamente más próximas al domicilio (tres públicas y tres concertadas) como escuelas de proximidad. De este modo, el sistema garantizaba una capacidad mínima de elección y la posibilidad de que aquellas familias residentes en zonas fronterizas pudieran tener acceso a las escuelas más cercanas a sus hogares, aunque no estuvieran situadas dentro de su área de influencia. La residencia de los estudiantes y el número de escuelas públicas y concertadas disponibles en el área de influencia y geográficamente más próximas determinan el conjunto de opciones de proximidad de cada estudiante.

En 2012, se aprobó una reforma para ampliar las posibilidades de elección. El número mínimo de escuelas consideradas como escuelas de proximidad se duplicó (seis escuelas públicas y seis concertadas). Considerando el exceso de oferta de escuelas en ciertas áreas de la ciudad, el promedio estimado de escuelas de proximidad por familia aumentó de 7,9 a 16,7 escuelas. ${ }^{2} \mathrm{Al}$ cambiar las posibilidades de elección de escuela, el CEB trató de compensar así la desigual distribución interna de las áreas de influencia escolar (que difieren tanto en el número total de escuelas como en la provisión público/privada).

El gobierno catalán presentó esta reforma en su momento como un mecanismo para reducir la fuerte relación entre la segregación residencial y la segregación escolar (Bonal y Verger, 2013). Al permitir mayores posibilidades de elección, se esperaba que las familias que viven en los barrios más pobres de la ciudad tendrían mayores posibilidades de salida de su zona, lo que reduciría la segregación escolar general. Sin embargo, y a pesar de que no existe una evaluación específica de los efectos de la ampliación de las posibilidades de elección de escuela, la segregación escolar en Barcelona se mantuvo estable entre 2006 y 2016, e incluso aumentó ligeramente en algunos distritos (Síndic de Greuges, 2016).

Este diseño institucional único, que combina la existencia de distritos escolares que no pueden considerarse espacios completamente cerrados con niveles significativos de elección de escuela, genera dinámicas de escolarización variables y altamente condicionadas por las características del mercado educativo local. Es decir, la opción de las familias por una escuela de proximidad, de la propia zona de influencia o de fuera de la zona, depende de la distribución geográfica de las escuelas en la ciudad, el nivel de exceso de demanda en cada área de influencia y las preferencias de las familias por cierto tipo de escuelas. Todos estos factores inciden sobre la movilidad educativa y en sus efectos sobre la segregación escolar en el conjunto de la ciudad y entre las zonas escolares.

\section{Método}

Los análisis presentados en este artículo se elaboraron a partir de un conjunto de bases de datos proporcionadas por el CEB. En primer lugar, el registro del conjunto de alumnado

${ }^{2}$ Véase CEB. (2012). Inici del curs escolar 2012-2013. Dossier de prensa. https://www.edubcn.cat/rcs_gene/extra/O1_sala_de_premsa/O_Dossier_premsa_inici_curs_20 12_13.pdf 
cursando segundo ciclo de educación infantil y educación primaria. Además del conjunto de datos escolares contenidos en dicha base de datos, para cada uno de los alumnos residentes en Barcelona se dispuso de las coordenadas geográficas de su lugar de residencia. En segundo lugar, las bases de datos de alumnos beneficiarios de las ayudas del fondo de emergencia social y de la beca comedor. Si bien ambas bases de datos fueron debidamente anonimizadas, el identificador de alumno permitió el cruce de la información contenida en las mismas.

Pese a que diferentes indicadores de segregación y concentración se han calculado a lo largo del análisis, con el objetivo de simplificar la presentación de los resultados, en el presente artículo se hace uso únicamente del índice de disimilitud, tanto para el cálculo de la segregación escolar como residencial. Este índice permite estimar el porcentaje de población perteneciente a la minoría que debería ser redistribuida entre las unidades de análisis para conseguir una distribución completamente equilibrada. En concreto, la fórmula de cálculo es la siguiente:

$$
D=\frac{1}{2} \sum_{i=1}^{n}\left|\frac{x_{i}}{X}-\frac{y_{i}}{Y}\right|
$$

donde $x_{i}$ corresponde al número de miembros de la población minoritaria en cada una de las unidades de análisis (i) y $X$ es el número total de miembros de la minoría en la zona de referencia (en nuestro caso el área de influencia o catchment area). Por su parte, $\mathrm{y}_{\mathrm{i}} \mathrm{e} \mathrm{Y}$ se corresponden con el número de miembros de la población mayoritaria en la unidad de análisis y para el conjunto de la zona de referencia respectivamente. En el caso de la segregación escolar, la unidad de análisis se corresponde con cada uno de los centros educativos, mientras que en el caso de la segregación residencial se tomó como unidad de referencia las diferentes secciones censales $(\mathrm{n}=1.068)$ que conforman la ciudad de Barcelona ${ }^{3}$.

Las bases de datos proporcionadas por el CEB permitieron analizar la distribución geográfica de la oferta escolar según la composición social de los distintos territorios, la segregación escolar de tres identificadores de alumnado vulnerable (nacionalidad extranjera, receptores de beca de comedor y receptores de ayudas del fondo social de emergencia) y las pautas de movilidad del alumnado entre las distintas áreas de influencia (catchment areas). El cuadro 1 resume las principales características de la muestra de alumnos y centros educativos analizados.

Por último, para estimar el impacto de la elección de escuela en la segregación escolar se simularon dos escenarios alternativos de escolarización:

- Escolarización en la zona educativa de residencia. En este escenario únicamente se reasignaron aquellos alumnos escolarizados en un centro educativo fuera de su zona educativa de residencia. Con este objetivo, los alumnos fueron distribuidos de manera aleatoria en alguno de los centros educativos situados en su zona de residencia independientemente de la titularidad del centro.

\footnotetext{
${ }^{3}$ Cabe señalar que para el cálculo de la segregación residencial únicamente se tuvieron en cuenta aquellas secciones censales en las cuales residen alumnos escolarizados en la ciudad de Barcelona que cursan segundo ciclo de educación infantil o educación primaria.
} 
- Escolarización en el centro más cercano. En este escenario todos los alumnos se asignaron a la escuela geográficamente más cercana a su lugar de residencia.

Cuadro 1. Características de la muestra de alumnado y centros escolares

\begin{tabular}{lrc}
\hline & NúMERO & \% SOBRE EL TOTAL \\
\hline Total alumnos & 105.254 & 100,0 \\
\hline Subgrupos de alumnos & & \\
$\quad$ Beca comedor & 20.233 & 19,2 \\
Fondo social & 9.399 & 8,9 \\
$\quad$ Extranjero & 15.961 & 15,2 \\
\hline Titularidad del centro & & \\
$\quad$ Público & 49.025 & 46,6 \\
$\quad$ Privado & 56.229 & 53,4 \\
\hline Centros educativos & 331 & 100,0 \\
\hline Público & 167 & 50,5 \\
\hline Privado & 164 & 49,5 \\
\hline Funte: Elaboracion propia a par &
\end{tabular}

Fuente: Elaboración propia a partir de la base de datos del registro de alumnos (CEB).

En ambos escenarios, el índice de disimilitud fue calculado teniendo en cuenta la nueva distribución del alumnado entre los diferentes centros educativos y los cambios en la composición de cada una de las zonas educativas y unidades de análisis. Por último, cabe señalar que el análisis se restringió al alumnado escolarizado y residente en Barcelona, excluyendo a aquellos alumnos que residen en otros municipios.

\section{Resultados}

\subsection{La desigual distribución de la oferta escolar en la ciudad y la segregación del alumnado}

Para comprender la relación entre elección de escuela y segregación escolar del alumnado socialmente más desfavorecido es importante observar cómo de equilibrada o desequilibrada es la oferta educativa de la ciudad desde un punto de vista territorial. Como se puede constatar en el mapa 1, el desequilibrio en la oferta de plazas de en el primer curso de educación infantil de segundo ciclo respecto a la población residente se sitúa lejos del equilibrio. Porcentajes por encima de 100\% indican una situación de sobreoferta respecto a la población residente, mientras que porcentajes inferiores reflejan situaciones de infraoferta. El desequilibrio se materializa en situaciones de sobreoferta en los territorios con mayor nivel de renta de la ciudad y, en cambio, en situaciones de infraoferta en las zonas educativas de menor renta (en algunas zonas por debajo del $80 \%$ y en alguna en particular por debajo del 60\%). Con la excepción de una única zona, las situaciones de sobreoferta se deben a un exceso significativo de plazas de titularidad privada-concertada en la ciudad. Lejos de compensar los déficits de escolarización, la oferta escolar concertada actúa desequilibrando las posibilidades de elección en los distintos territorios de la ciudad (Bonal y Zancajo, 2018b).

El "negativo" del mapa de la oferta de plazas se puede observar en el mapa 2, que presenta la distribución de la población según nivel de estudios como un proxy del nivel socioeconómico de cada una de las zonas. La concentración de niveles de estudios bajos tiene lugar en la periferia de la ciudad. Por contra, la población con mejor nivel de estudios 
se sitúa en las zonas económicamente más favorecidas, que coinciden con ser las de mayor oferta escolar.

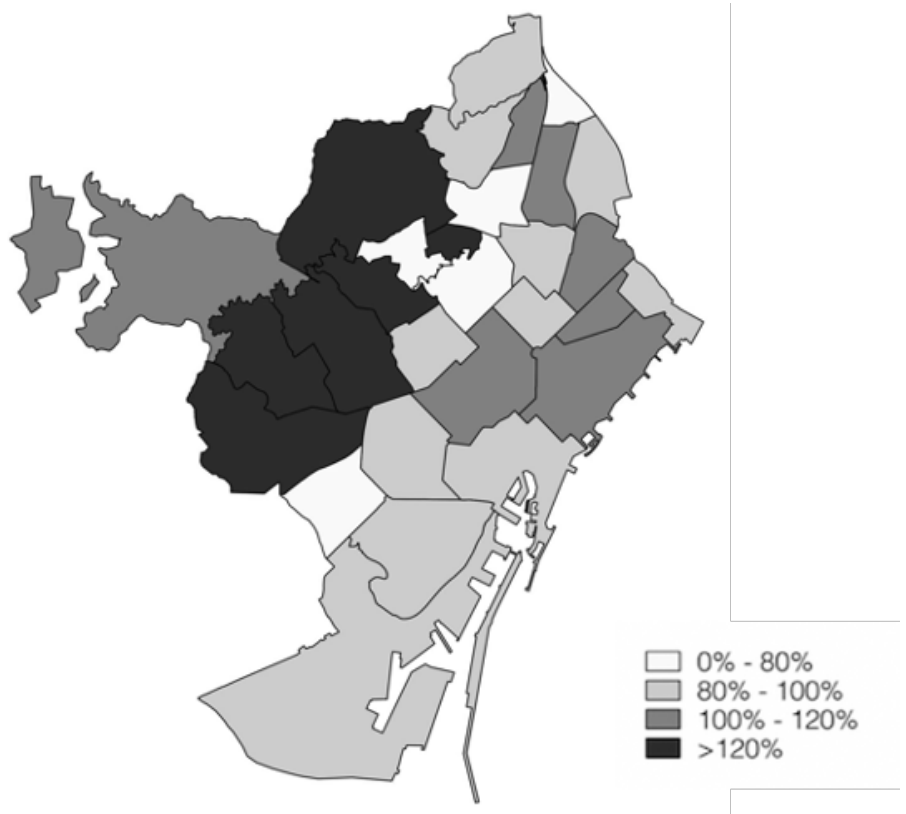

Mapa 1. Zonas educativas según proporción de oferta de plazas respecto a la población residente. Primer curso de educación infantil de segundo ciclo, curso 2016-17

Fuente: Elaboración propia a partir de datos de padrón y oferta de plazas escolares facilitados por el CEB.

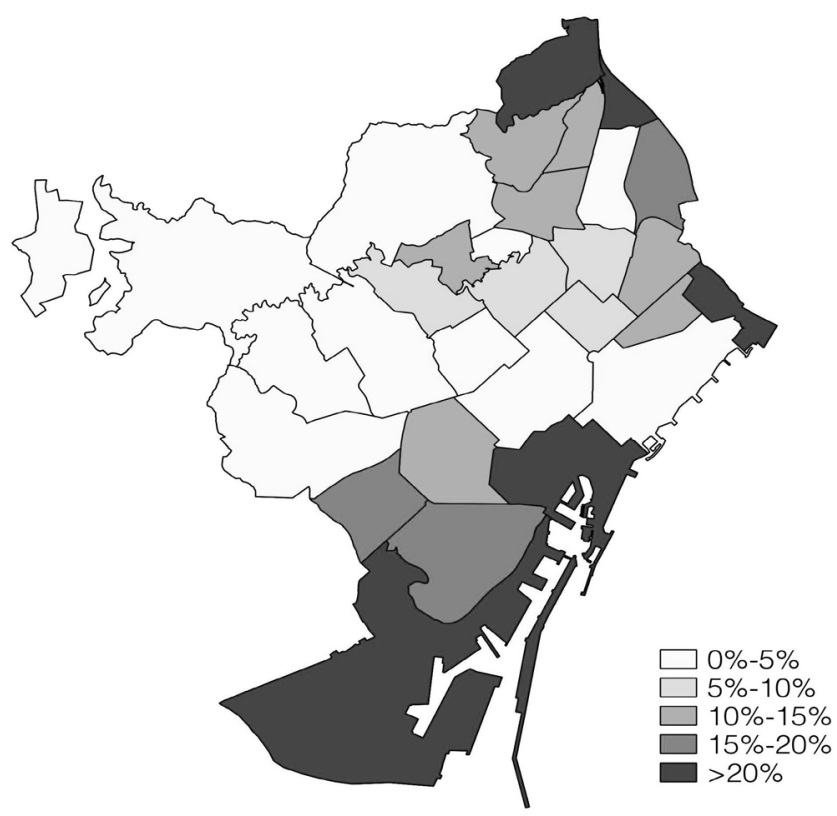

Mapa 2. Distribución de la media de alumnado de familias con nivel de estudios bajos según zona educativa, curso 2016-17

Nota: Estudios bajos incluye las categorías de padres y/o tutores que no saben leer y escribir, los que tienen una titulación inferior al grado de escolaridad y los que no tienen estudios.

Fuente: Elaboración propia a partir de datos facilitados por el CEB. 
Las diferencias territoriales en la estructura de la oferta escolar, sin embargo, no tienen una correspondencia perfecta con los niveles de segregación escolar del alumnado. El mapa 3 presenta los índices de segregación escolar de tres subgrupos de estudiantes vulnerables de educación infantil y primaria: receptores de beca de comedor (variable que suele utilizarse como indicador de pobreza), receptores de ayudas del fondo social de emergencia (otorgado por el ayuntamiento a familias en situación de pobreza severa) y alumnado extranjero. En primer lugar, puede observarse que el nivel de segregación escolar para los tres subgrupos de alumnado analizado es muy diverso en el conjunto de la ciudad. Mientras en algunas zonas educativas los índices de disimilitud no superan el 0,2, en otras se sitúan por encima del 0,5.

Puede observarse también que existen diferencias en la segregación escolar de los distintos subgrupos (especialmente del alumnado extranjero en comparación con el alumnado en situación de pobreza). Asimismo, la segregación escolar del alumnado es situación de pobreza o exclusión social es más alta en las zonas de los distritos socioeconómicamente más favorecidos, con la excepción de dos zonas del este de la ciudad. Las diferencias en la segregación escolar del alumnado extranjero también son pronunciadas -aunque con menor intensidad- entre distintas zonas de la ciudad. En este caso la dispersión es mayor entre zonas más o menos favorecidas.

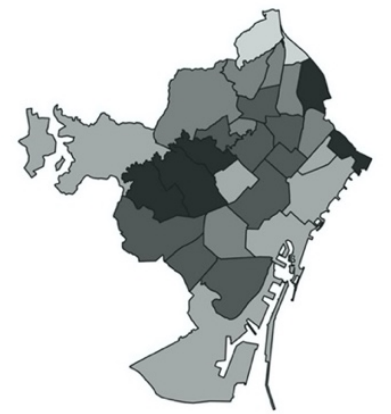

Beca comedor

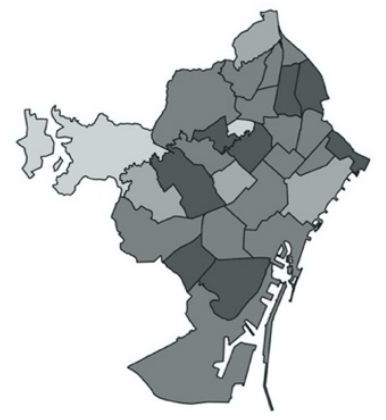

Extranjero

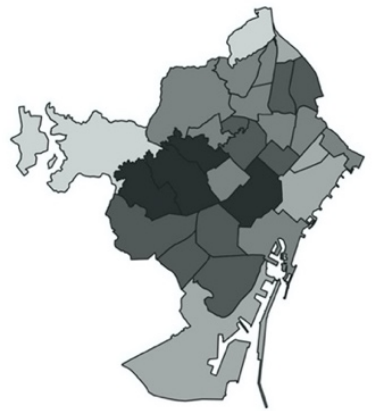

Fondo social

Índice de disimilitud

$\square 0:<0.1$

$\square 0.1:<0.2$

$\square 0.2:<0.3$

$\square 0.3:<0.4$

$\square .4:<0.5$

$\square 0.5$

Mapa 3. Segregación escolar según subgrupo de alumnado y zona educativa, curso 201617

Fuente: Elaboración propia a partir de la base de datos del registro de alumnos (CEB).

A modo de resumen de la segregación escolar para el conjunto de la ciudad, el cuadro 2 recoge los principales estadísticos relativos a los índices de disimilitud del alumnado de 
cada subgrupo para el conjunto de zonas educativas de la ciudad. Puede observarse que el índice es, en promedio, algo superior en el caso de los receptores de becas de comedor o fondo social respecto al del alumnado extranjero, sin que las diferencias sean excesivamente relevantes. Asimismo, el rango es especialmente elevado en el caso del alumnado en situación de pobreza severa (receptores del fondo social), indicando una dispersión significativa entre las diferentes zonas educativas de la ciudad. Más allá de los casos extremos, la desviación estándar es relativamente similar para la segregación del alumnado receptor de beca comedor y de fondo social, mientras es algo más reducida en el caso de los alumnos de nacionalidad extranjera.

Cuadro 2. Estadísticos descriptivos del índice de disimilitud por zona educativas según subgrupo de alumnado, curso 2016-17

\begin{tabular}{lccc}
\hline & BECA COMEDOR & FONDO SOCIAL & EXTRANJERO \\
\hline Media & 0,39 & 0,39 & 0,35 \\
Mediana & 0,40 & 0,40 & 0,35 \\
Desviación estándar & 0,11 & 0,10 & 0,07 \\
Rango & 0,38 & 0,46 & 0,26 \\
Mínimo & 0,18 & 0,16 & 0,20 \\
Máximo & 0,56 & 0,62 & 0,46 \\
\hline
\end{tabular}

Fuente: Elaboración propia a partir de la base de datos del registro de alumnos (CEB).

¿Qué relación existe entre los niveles de segregación escolar y residencial para cada uno de los subgrupos? La figura 1 muestra tres gráficos que relacionan la segregación escolar y la segregación residencial, uno para cada subgrupo de alumnado. Puede observarse cómo en la mayoría de las zonas educativas la segregación escolar es significativamente mayor que la segregación residencial (todas aquellas zonas que se sitúan por encima de la línea de 45 grados). Esta tendencia es observable tanto para el alumnado beneficiario de beca comedor, fondo social o de nacionalidad extranjera.
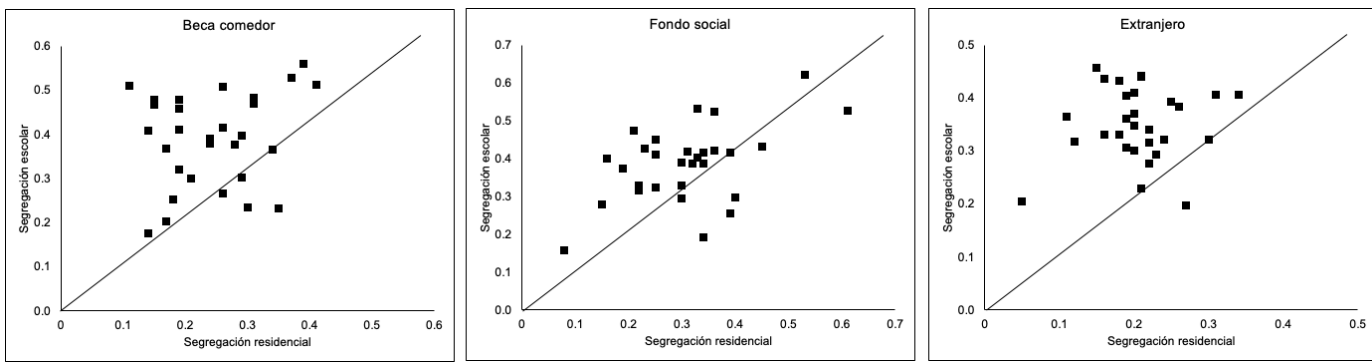

Figura 1. Relación entre segregación residencial i escolar según subgrupo de alumnado y zona educativa, curso 2016-17

Fuente: Elaboración propia a partir de la base de datos del registro de alumnos (CEB).

Puede observarse también cómo el comportamiento de esta diferencia es distinto entre las zonas en función del tipo de desigualdad considerada, por condición económica o por tratarse de alumnado extranjero. Los gráficos evidencian que la escolarización fuera de la zona de residencia tiende, casi siempre, a aumentar la segregación escolar del alumnado vulnerable. Las posibilidades de elección que otorga el actual sistema y los desequilibrios en la capacidad de escolarización de las zonas educativas son generadores de niveles de movilidad intra e interzonas que aumentan la segregación escolar. En el siguiente 
apartado nos ocupamos de mostrar las pautas de movilidad asociadas a la escolarización para los distintos grupos de alumnos.

\subsection{La movilidad escolar de los diferentes subgrupos de estudiantes}

Tal y como hemos señalado anteriormente, la política de admisión escolar de Barcelona permite niveles elevados de movilidad intraurbana por razones de escolarización. El sistema de asignación de las áreas de proximidad permite en muchos casos que las familias cuenten con la prioridad por proximidad incluso para acceder a algunas escuelas fuera de su zona de residencia. En otros casos, la elevada sobreoferta de plazas en el sector concertado explica la capacidad de algunas familias para acceder a centros educativos que se encuentran fuera de su área de influencia. Aquellas escuelas que no se encuentran en situación de sobredemanda durante el proceso de preinscripción no necesitan aplicar el criterio de proximidad. La figura 2 permite observar cómo los niveles de retención ${ }^{4}$ en las zonas educativas son, en general, bajos, con sólo tres zonas por encima del $80 \%$ de retención y varias zonas en las que menos del $70 \%$ del alumnado se escolariza en zonas distintas a la de su residencia. Esta baja retención en la zona, o elevada movilidad, se produce en general a centros de zonas adyacentes a la zona de residencia (Bonal y Zancajo, 2018b).

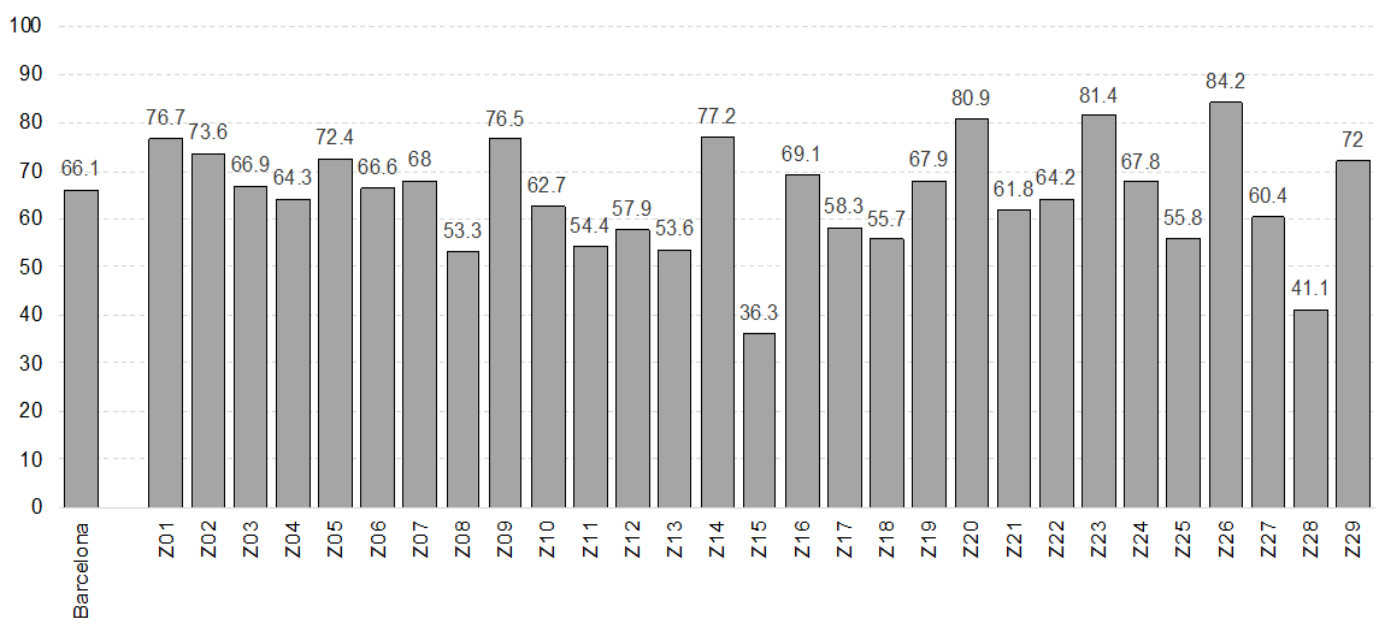

Figura 2. Porcentaje de alumnado de educación infantil y primaria matriculado en su zona escolar de residencia, curso 2016-17

Fuente: Elaboración propia a partir de la base de datos del registro de alumnos (CEB).

Sin embargo, los bajos niveles de retención en las diferentes zonas educativas de la ciudad esconden importantes desigualdades según las características del alumnado y según el tipo de alumnado que se escolariza fuera de su zona de residencia. La figura 3 muestra la ratio entre el porcentaje de los alumnos de cada uno de los subgrupos analizados y el resto del alumnado que opta por escolarizarse en su zona educativa de residencia. Los valores superiores a 1 indican una mayor probabilidad de no abandonar la zona de residencia para escolarizarse de aquellos alumnos que no pertenecen al subgrupo de referencia. Como puede observarse en la figura, en la mayoría de las zonas educativas los alumnos pertenecientes a alguno de los subgrupos analizados presentan una mayor probabilidad

${ }^{4} \mathrm{El}$ nivel de retención de las zonas de influencia se ha definido como el porcentaje de alumnos que se escolariza en su zona de influencia de residencia. 
de escolarizarse en su zona de residencia en comparación con el resto del alumnado. De hecho, en muchas zonas educativas de la ciudad el alumnado beneficiario de beca comedor, fondo social o de nacionalidad extranjera tiene una probabilidad de escolarizarse en su zona de residencia más de un $20 \%$ superior al resto de los alumnos.

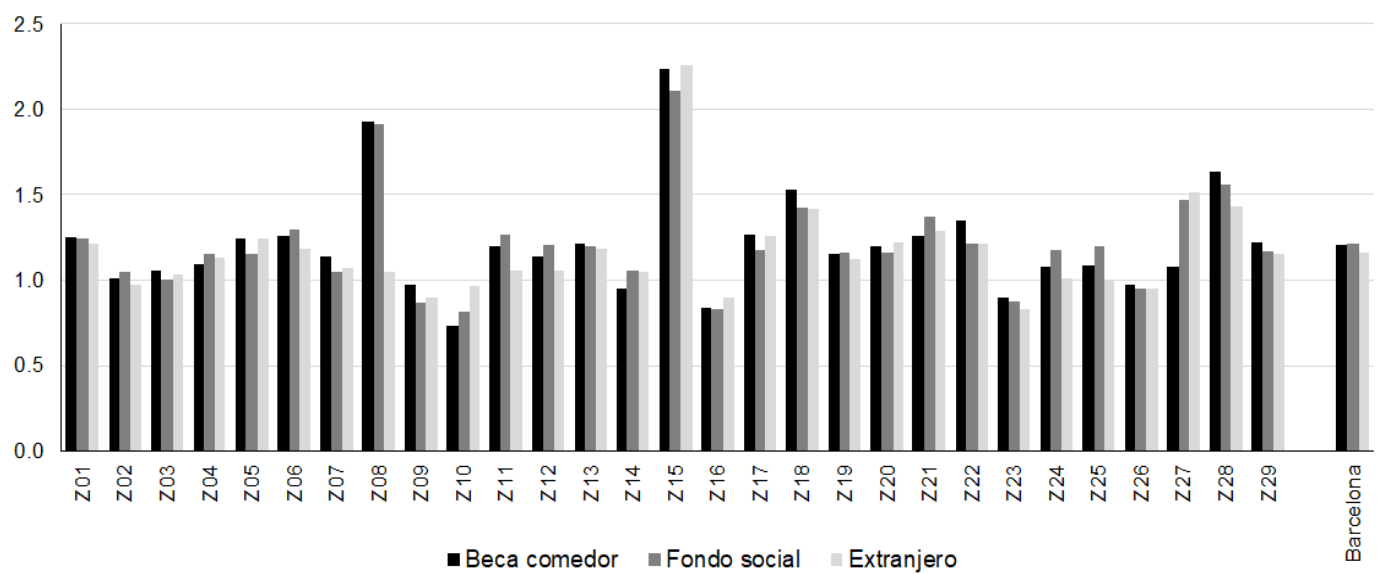

Figura 3. Ratio entre el porcentaje el alumnado de cada subgrupo y el resto de alumnado que se escolariza en su zona de residencia, curso 2016-17

Fuente: Elaboración propia a partir de la base de datos del registro de alumnos (CEB).

Una situación similar se puede observar cuando se evalúa la escolarización de proximidad, es decir, en el centro más cercano al domicilio. Como muestra la figura 4, para el conjunto de la ciudad, únicamente alrededor del $18 \%$ de los alumnos se escolariza en el centro educativo más cercano a su domicilio. Sin embargo, las diferencias entre zonas educativas en este indicador son significativas. Mientras en algunas zonas educativas casi el $40 \%$ del alumnado se escolariza en el centro más cercano, esta proporción se reduce a niveles próximos al $10 \%$ en otras zonas.

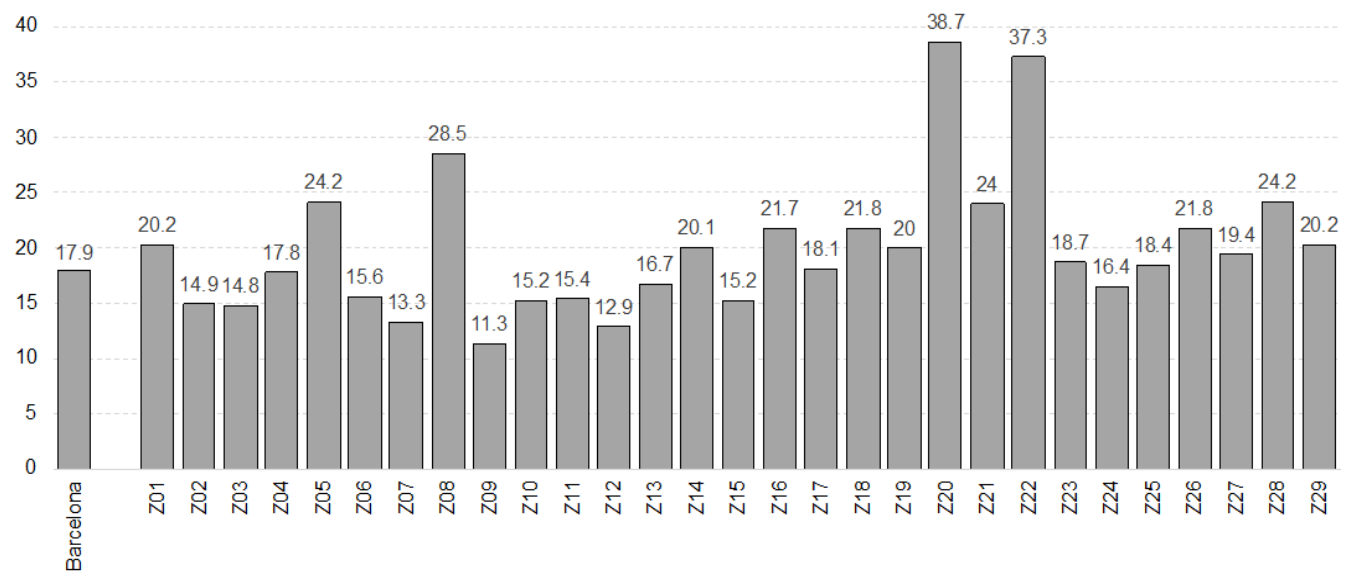

Figura 4. Porcentaje de alumnado de educación infantil y primaria en el centro educativo más cercano a su domicilio, curso 2016-17

Fuente: Elaboración propia a partir de la base de datos del registro de alumnos (CEB).

Como en el caso de la escolarización en la zona educativa de residencia, la prevalencia de la escolarización de proximidad se ve influida por las características socioeconómicas del alumnado (figura 5). De nuevo, el alumnado de alguno de los subgrupos de vulnerabilidad 
es más propenso a escolarizarse en el centro educativo más cercano a su domicilio que el resto de los alumnos. Si tomamos en consideración la media para el conjunto de la ciudad, estas diferencias son algo más importantes en el caso de los alumnos beneficiarios del fondo social o de nacionalidad extranjera en comparación con los alumnos receptores de beca comedor.

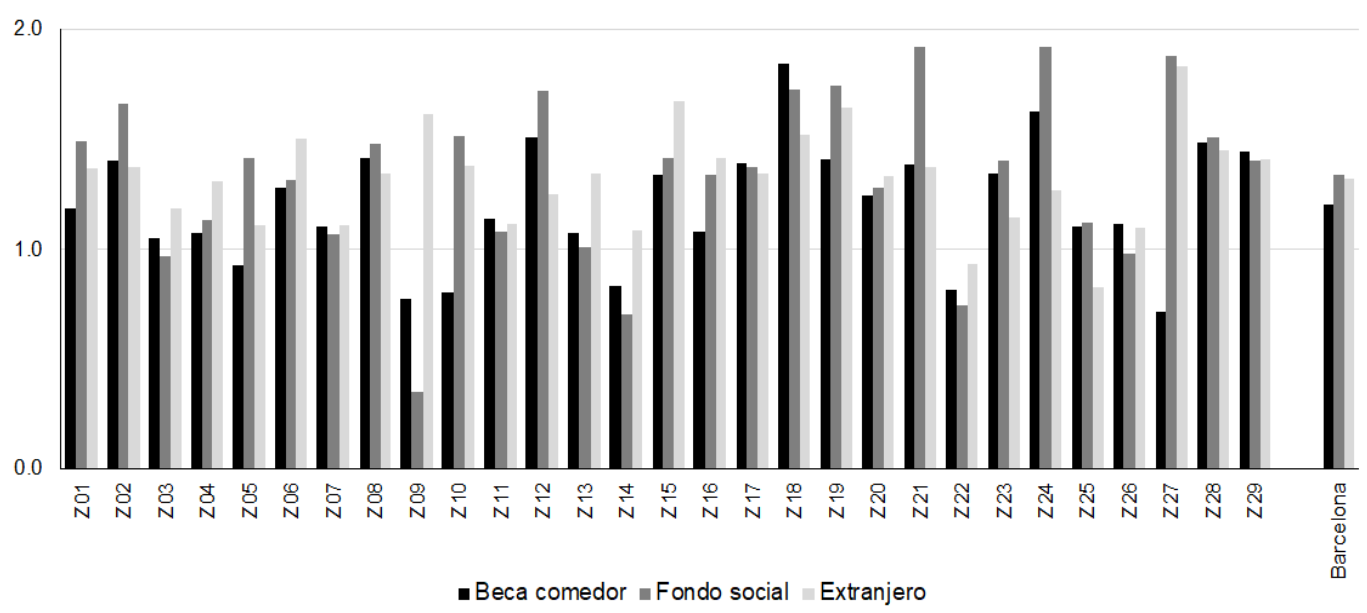

Figura 5. Ratio entre el porcentaje el alumnado de cada subgrupo y el resto de alumnado que se escolariza en el centro más cercano a su domicilio, curso 2016-17

Fuente: Elaboración propia a partir de la base de datos del registro de alumnos (CEB).

En definitiva, los resultados presentados en este apartado muestran como el alumnado de subgrupos más vulnerables, en términos generales, muestra una mayor movilidad interzonas e intrazonas que el resto de alumnado. Es evidente que la diferencia observada entre segregación residencial y escolar es un fenómeno complejo que puede responder a una multiplicidad de factores. Sin embargo, las desigualdades en la movilidad escolar podrían ser el origen de buena parte de las diferencias observadas. En este sentido, las diferencias entre segregación residencial y escolar pueden explicarse por las pautas diferenciadas de movilidad entre grupos sociales, tanto entre zonas educativas (interzonas), como dentro de las zonas educativas (intrazonas). El siguiente apartado analiza de qué manera los diferentes patrones de movilidad según las características socioeconómicas de alumnado pueden incidir sobre la segregación escolar.

\subsection{El efecto de la movilidad sobre la segregación escolar: Un análisis contrafactual}

Observadas las pautas de movilidad desiguales por subgrupos de alumnos y por zonas educativas, en esta última sección nos centramos en analizar hasta qué punto el efecto de la movilidad del alumnado es o no generador de mayores niveles de segregación escolar. Como hemos señalado en el apartado anterior, las pautas de movilidad analizadas permiten contemplar la hipótesis de que la movilidad por escolarización es uno de los principales factores explicativos de la diferencia entre segregación residencial y escolar.

Un método para contrastar esta hipótesis es el del análisis contrafactual, tal como ha puesto de relieve la revisión de la literatura en la primera sección de este artículo. El análisis contrafactual permite comparar escenarios reales con escenarios simulados de escolarización. Como se ha mencionado en el apartado metodológico, en este caso, definimos dos tipos de escenarios simulados: la escolarización exclusivamente dentro de la zona educativa, y la escolarización en la escuela geográficamente más cercana al 
domicilio del alumno. Esta aproximación permite comparar la segregación escolar, a partir de los índices de disimilitud, en el escenario real y en los escenarios simulados para los tres subgrupos de alumnado analizados. Cabe señalar que ambos escenarios simulados asumen la existencia de suficientes plazas escolares para el alumnado residente en cada zona y escuela, un hecho que como hemos visto no se corresponde con la distribución actual de la oferta escolar. En todo caso, el análisis contrafactual es un ejercicio de carácter teórico que nos acerca a valorar el efecto agregado de la movilidad sobre la segregación escolar y la desigualdad educativa.

La figura 4 muestra la relación entre la segregación escolar en el escenario real y los dos escenarios simulados para cada una de las zonas educativas de la ciudad. Los puntos situados por debajo de la línea diagonal de 45 grados indican una reducción de la segregación escolar en el escenario simulado y el real. Por otro lado, el coeficiente de la variable equis (segregación en el escenario real) nos aporta un indicador de la intensidad de la reducción de la segregación entre el escenario real y simulado. En este caso, valores inferiores de dicho coeficiente indican una mayor reducción media de la segregación entre los dos escenarios comparados. En el caso del escenario en el que todos los alumnos se escolarizan en su zona educativa de residencia, se puede observar que en casi todas las zonas educativas (salvo un caso), la segregación escolar se reduce de manera significativa. La misma tendencia, incluso más acentuada, se observa cuando se compara la segregación escolar en el escenario real y el de escolarización en el centro más cercano. De nuevo, en la mayoría de las zonas educativas la segregación escolar en el escenario de centro más cercano disminuye de manera considerable respecto a la observada en el escenario real. El coeficiente de la reducción es significativamente mayor en el escenario de centro cercano $(0,21)$ en comparación con el escenario de escolarización en la zona educativa de residencia $(0,34)$.

En el caso del alumnado beneficiario de las ayudas del fondo social (figura 5) y el alumnado de nacionalidad extranjera (figura 6) la tendencia es muy similar a la observada para los alumnos con beca comedor. En ambos casos, se puede observar como en la gran mayoría de zonas educativas la segregación escolar en los escenarios simulados es significativamente inferior a la del escenario real. Como en el caso de los alumnos con beca comedor, si se comparan los coeficientes de reducción, para los alumnos beneficiarios de fondo social y de nacionalidad extranjera la reducción de la segregación escolar es mucho más intensa en el escenario de escolarización en el centro cercano que en el de zona educativa.

Por último, cabe señalar que las zonas educativas que en algunas ocasiones se comportan como un outlier, es decir aquellas donde la segregación escolar en los escenarios simulados es mayor que en el escenario real, se corresponden con zonas con características geográficas o de oferta educativa particulares. De hecho, en la gran mayoría de casos se trata de la zona educativa 8 , situada en la parte más alta de la ciudad, con una geografía y una distribución de la oferta educativa muy peculiar que no se corresponde con el resto de las zonas educativas. La zona educativa 14 que también presenta este comportamiento en el caso del alumnado de nacionalidad extranjera, tiene características específicas relativas a la oferta educativa que podría explicar dicho comportamiento. 

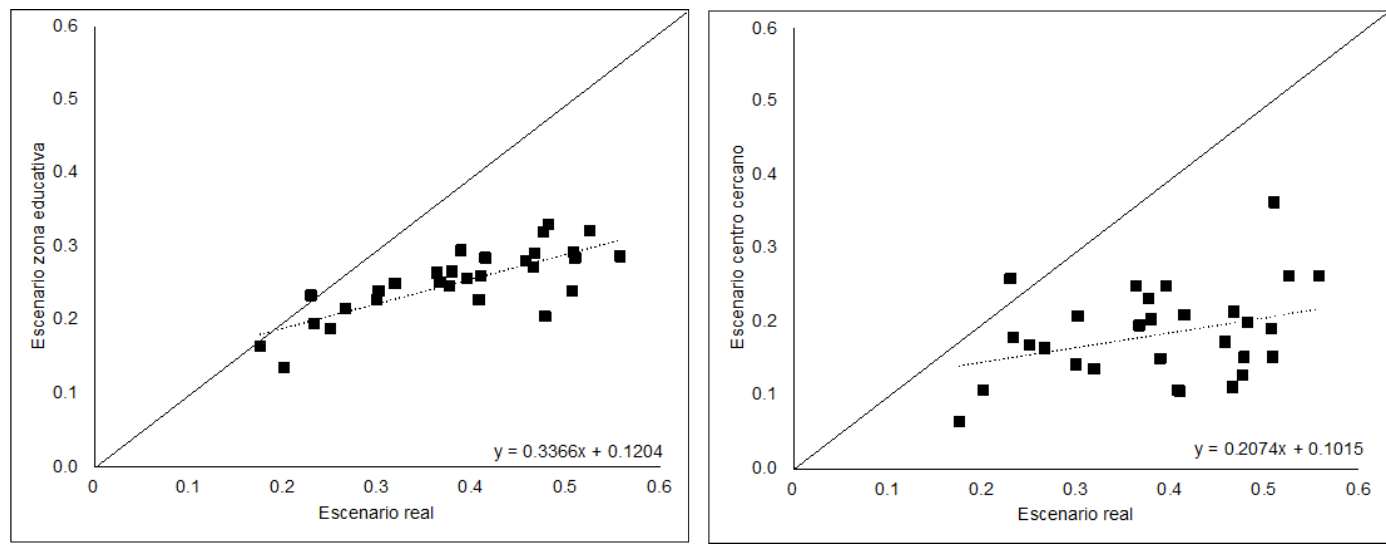

Figura 4. Índice de disimilitud del alumnado receptor de beca de comedor según escenario y zona educativa de residencia, curso 2016-17

Fuente: Elaboración propia a partir de la base de datos del registro de alumnos (CEB).
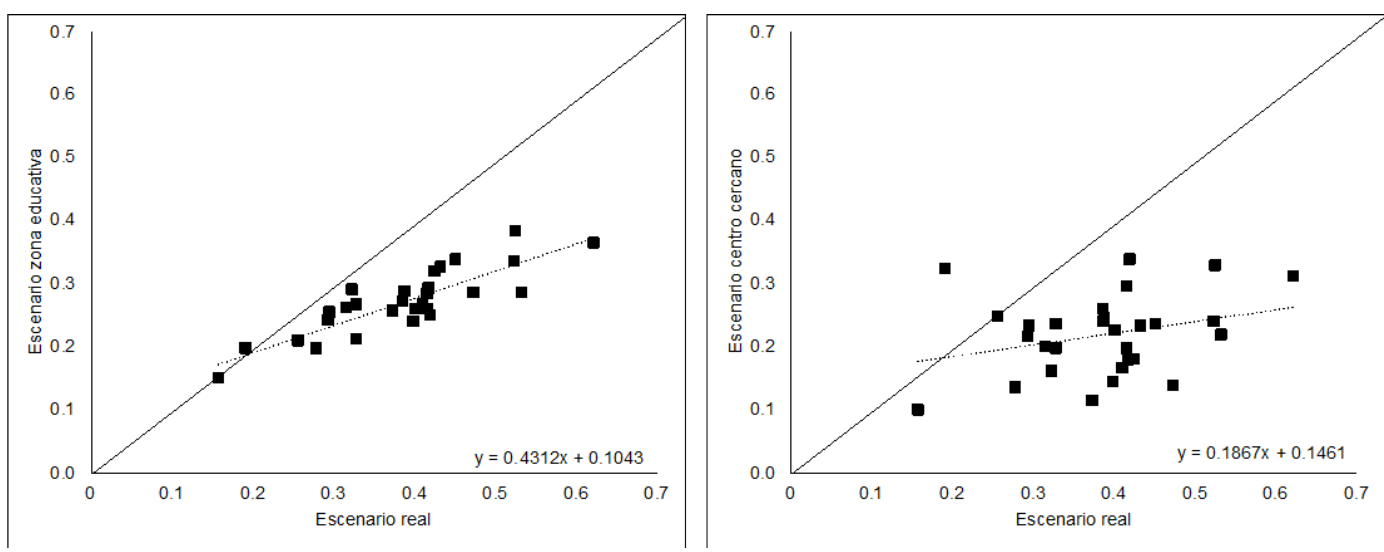

Figura 5. Índice de disimilitud del alumnado receptor de ayudas del fondo social de emergencia según escenario y zona educativa de residencia, curso 2016-17

Fuente: Elaboración propia a partir de la base de datos del registro de alumnos (CEB).
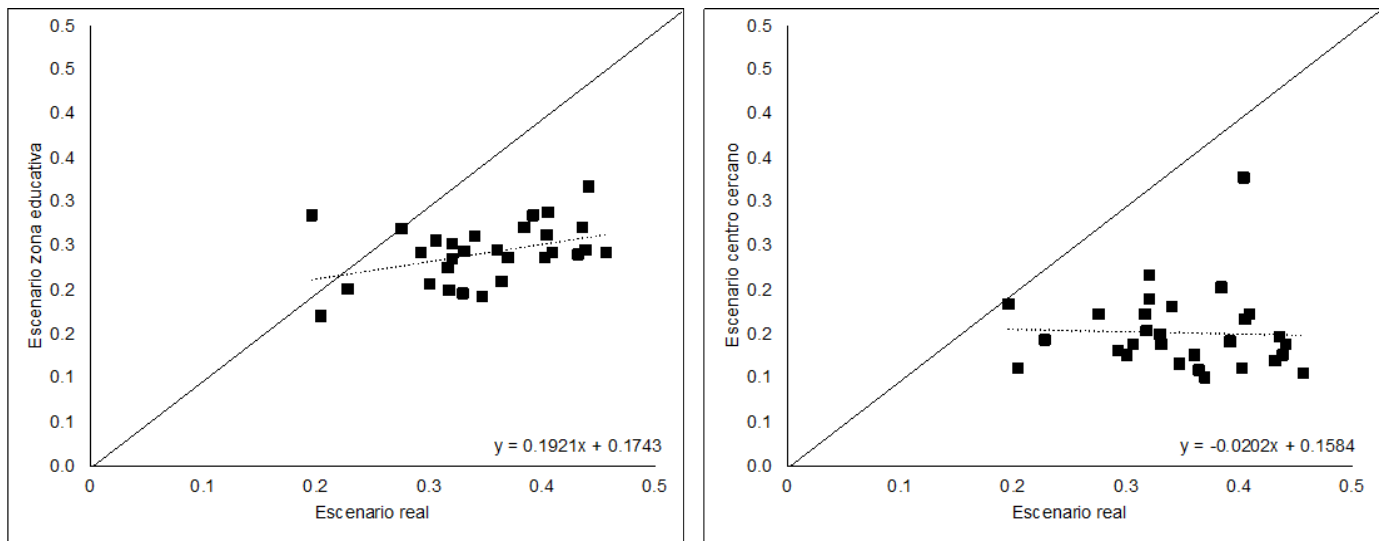

Figura 6. Índice de disimilitud del alumnado extranjero según escenario y zona educativa de residencia, curso 2016-17

Fuente: Elaboración propia a partir de la base de datos del registro de alumnos (CEB). 
A modo de resumen, el cuadro 3 muestra la media para las 29 zonas educativas de los índices de disimilitud para cada uno de los escenarios analizados. Como se puede observar, para los tres subgrupos la reducción media de la segregación escolar entre el escenario real y el de escolarización se sitúa entre el 35,3\% y el 29,8\%, siendo la segregación escolar del alumnado receptor de beca comedor el que experimenta una mayor reducción. En el caso del escenario de escolarización en el centro más cercano la reducción se sitúa entre el $43,4 \%$ para los alumnos beneficiarios de las ayudas de fondo social, y el 56,7\% para el alumnado de nacionalidad extranjera.

Cuadro 3. Media del índice disimilitud de las ZE según escenarios y subgrupo de alumnos, curso 2016-17

\begin{tabular}{lccccc}
\hline & $\begin{array}{c}\text { ESCENARIO } \\
\text { REAL }\end{array}$ & \multicolumn{2}{c}{ ZoNA EDUCATIVA } & \multicolumn{2}{c}{ CENTRO MÁs CERCANO } \\
\cline { 2 - 6 } & $\begin{array}{c}\text { Segregación } \\
\text { escolar }\end{array}$ & $\begin{array}{c}\text { Segregación } \\
\text { escolar }\end{array}$ & $\begin{array}{c}\text { \% respecto } \\
\text { escenario } \\
\text { real }\end{array}$ & $\begin{array}{c}\text { Segregación } \\
\text { escolar }\end{array}$ & $\begin{array}{c}\text { \% respecto } \\
\text { escenario } \\
\text { real }\end{array}$ \\
\hline Beca comedor & 0,39 & 0,25 & $-35,3$ & 0,18 & $-53,1$ \\
Fondo social & 0,39 & 0,27 & $-29,8$ & 0,22 & $-43,4$ \\
Extranjero & 0,35 & 0,24 & $-31,0$ & 0,15 & $-56,7$ \\
\hline
\end{tabular}

Fuente: Elaboración propia a partir de la base de datos del registro de alumnos (CEB).

Una comparación más detallada de las diferencias entre zonas requeriría un análisis de las pautas de movilidad a partir de datos individuales, ya que los factores que potencialmente podrían explicar las diferencias entre los diferentes escenarios y subgrupos de alumnos son de índole diversa. En primer lugar, las diferencias en el peso porcentual de cada uno de los colectivos en las diferentes zonas educativas de la ciudad pueden influir en el hecho que los escenarios simulados provoquen una mayor o menor reducción de la segregación escolar. En segundo lugar, la distribución residencial de los subgrupos analizados afecta a la capacidad del escenario de centro más cercano para reducir la segregación escolar. La concentración residencial (guetos) de algunos de estos subgrupos en algunas áreas de las zonas educativas de la ciudad influye en la capacidad de la escolarización de proximidad para reducir la segregación escolar. Con todo, el análisis contrafactual es ilustrativo de la polarización en el proceso de escolarización y de los efectos negativos de un sistema que favorece la elección escolar hasta el punto de reducir significativamente la escolarización de proximidad.

Finalmente, un último indicador de la estratificación social derivada de la movilidad por escolarización se puede observar en la figura 7 . El gráfico recoge la ratio del porcentaje de cada subgrupo de alumnado vulnerable entre los centros educativos públicos y privados concertados en el escenario real y en los dos escenarios simulados. Puede observarse en todos los casos niveles superiores de sobre escolarización del alumnado socialmente más desfavorecido en el sector público. Las ratios son especialmente elevadas en el escenario real, con índices superiores de sobre escolarización hasta 5,5 veces más en el caso del alumnado del fondo social o de 2,5 en el caso del alumnado extranjero. En todos los casos el desequilibrio entre centros públicos y concertados se reduciría significativamente en los escenarios simulados, y lo haría de forma drástica en el escenario de escolarización en el centro más cercano, donde la escolarización entre sectores prácticamente se equilibraría en el caso del alumnado extranjero. 


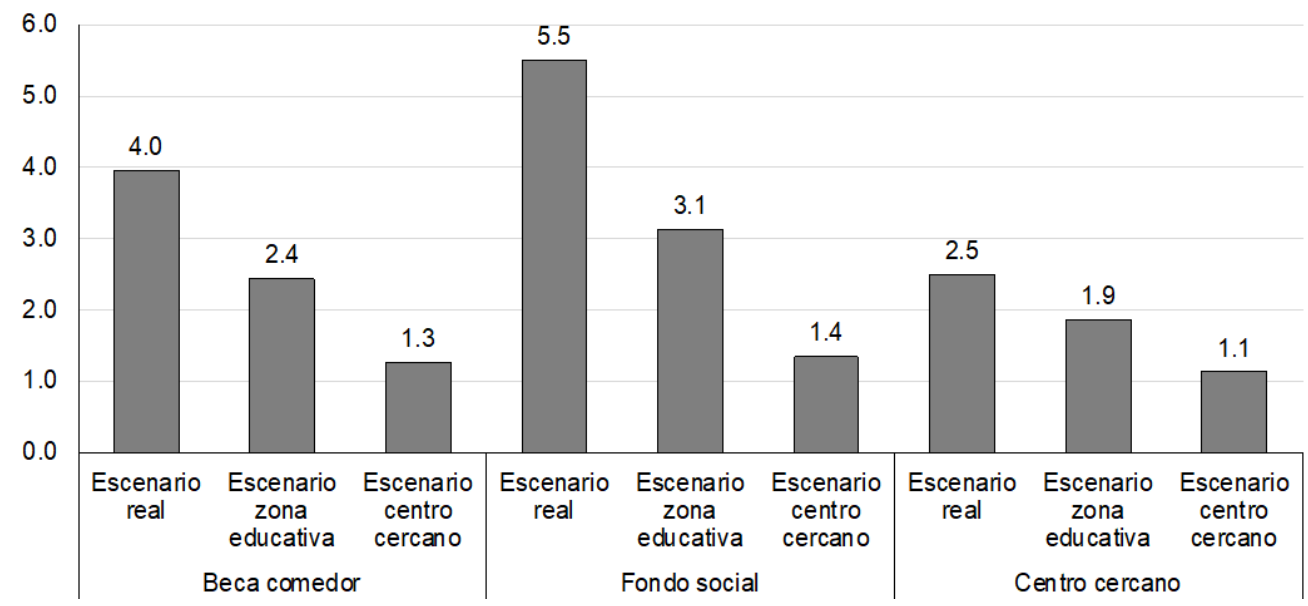

Figura 7. Estratificación entre centros públicos y concertados, según subgrupo de alumnado y escenario, curso 2016-17

Nota: El gráfico expone para cada escenario y subgrupo de alumnado la ratio de sobre escolarización en el sector público respecto al concertado.

Fuente: Elaboración propia a partir de la base de datos del registro de alumnos (CEB).

\section{Conclusiones y recomendaciones de política educativa}

Los datos relativos a la escolarización del alumnado en la educación infantil i primaria en la ciudad de Barcelona nos han revelado niveles significativos de segregación escolar asociados a los importantes niveles de movilidad escolar favorecidos por un sistema de otorga un amplio margen de elección a las familias. Las reformas en el sistema de zonificación escolar aplicadas en la ciudad en los años 2006 y 2012, y el consiguiente aumento en las posibilidades de elección, facilitaron una mayor movilidad por escolarización que se han traducido en niveles de segregación escolar superiores a la segregación residencial. Los análisis presentados en este artículo revelan esta pauta común para todos los subgrupos de alumnado por condición socioeconómica y nacionalidad. Sin embargo, existen pautas de segregación escolar de cada subgrupo diferenciadas entre zonas de influencia, especialmente entre el alumnado extranjero y el alumnado en situación de pobreza. La distribución geográfica de cada subgrupo y las oportunidades de movilidad en cada territorio son posiblemente factores que explican estas diferencias.

Como hemos señalado en un trabajo anterior (Bonal y Zancajo, 2019), las pautas de movilidad educativa dependen en gran medida de las características de los mercados educativos locales: situaciones de infra o sobreoferta escolar, presencia de escuela concertada y niveles de segregación residencial se combinan para explicar pautas de movilidad y de polarización social. En todo caso, el resultado agregado es claramente perjudicial desde un punto de vista de equidad. El análisis contrafactual nos ofrece una panorámica de la desigualdad en la que se reproduce lo observado en otros sistemas educativos; es decir, una reducción significativa de la segregación cuando aumenta la escolarización de proximidad (Allen, 2007; Bifulco, Ladd y Ross, 2009).

A partir del análisis presentado en el presente artículo pueden realizarse algunas consideraciones desde el punto de vista de las políticas educativas encaminadas a mejorar la equidad y reducir la segregación escolar. Es evidente que el conjunto de medidas 
posibles es amplio y escapa a los objetivos y posibilidades de este artículo. Nos limitaremos por ello a señalar dos cuestiones que parecen clave desde el punto de vista de la relación entre movilidad por escolarización y segregación escolar. En primer lugar, carece de sentido disponer de zonas de escolarización tan desequilibradas desde un punto de vista demográfico. Los niveles de infra o sobre escolarización revelan un problema de estructura de la oferta escolar. En ocasiones estos desequilibrios son difíciles de corregir debido a la concentración de escuelas en determinadas zonas, y especialmente de escuelas concertadas (es el caso por ejemplo de la elevada sobreoferta en los distritos de mayor nivel socioeconómico). Sin embargo, buena parte del desequilibrio se podría corregir rediseñando algunas zonas para conseguir un mejor equilibrio entre oferta y demanda educativa, así como ajustando el número de plazas en aquellas zonas con mayor sobreoferta. A modo de ejemplo, carece de sentido que exista una zona con una cobertura de plazas respecto a la población residente cercana al $400 \%$ colindante con una zona con el $54 \%$ de cobertura.

En segundo lugar, y en relación con lo anterior, las virtudes de un sistema de acceso a la escolarización que tiene como objetivo equilibrar el mínimo número de opciones de elección desaparecen, paradójicamente, a causa del elevado número de posibilidades de escolarización (12 escuelas como mínimo) y de un modelo que integra las propias áreas de influencia al cálculo de la proximidad (lo que da como resultado una media real de elección de 16,7 escuelas por familia). Parecería razonable, si se opta por un sistema de equidad en las opciones de escolarización, equilibrar las zonas (como ya hemos señalado) o suprimirlas del todo y optar por un modelo exclusivamente de proximidad geográfica. El resultado del análisis contrafactual nos indica claros beneficios de optar por un sistema que refuerce la proximidad en la escolarización, al reducirse la segregación en ocasiones hasta niveles del $50 \%$ o más.

Evidentemente, se trata de propuestas que deben ser estudiadas con detenimiento y observadas en cada mercado educativo local para valorar su impacto. En todo caso, parece claro que mantener un sistema como el actual, con notables márgenes de elección escolar en un mercado educativo desigual y con fuerte presencia de escuela concertada, no constituye una buena opción desde el punto de vista de la equidad educativa.

\section{Referencias}

Alegre, M. A. y Ferrer, G. (2010). School regimes and education equity: Some insights based on PISA 2006. British Educational Research Journal, 36(3), 433-461. https://doi.org/10.1080/01411920902989193

Allen, R. (2007). Allocating pupils to their nearest secondary school: The consequences for social and ability stratification. Urban Studies, 44(4), 751-770. https://doi.org/10.1080/00420980601184737

Archbald, D. A. (2003). School choice, magnet schools, and the liberation model: An empirical study. Sociology of Education, 77, 283-310. https://doi.org/10.1 177/003804070407700402

Ball, S. J. (1998). Big policies/small world: An introduction to international perspectives in education policy. Comparative Education, 34(2), 119-130. https://doi.org/10.1080/03050069828225

Ben-Porath, S. R. (2009). School choice as a bounded ideal. Journal of Philosophy of Education, 43, 527-544. https://doi.org/10.1111/j.1467-9752.2009.00726.x 
Bifulco, R., Ladd, H. F. y Ross, S. L. (2009). Public school choice and integration evidence from Durham, North Carolina. Social Science Research, 38(1), 71-85. https://doi.org/10.1016/j.ssresearch.2008.10.001

Bonal, X. y Verger, A. (2013). L’agenda de la política educativa a Catalunya: Una anàlisi de les opcions de govern (2011-2013). Fundació Jaume Bofill.

Bonal, X. y Zancajo, A. (2018a). Demand rationalities in contexts of poverty: Do the poor respond to market incentives in the same way? International Journal of Educational Development, 59, 20-27. https://doi.org/10.1016/j.ijedudev.2017.10.001

Bonal, X. y Zancajo, A. (2018b). School segregation in the Spanish quasi-market. En X. Bonal y C. Bellei (Eds.), Understanding school segregation: Patterns, causes and consequences of spatial inequalities in education (pp. 201-220). Bloomsbury Academic.

Bonal X. y Zancajo, A. (2019). Equivalència territorial en la planificació educativa a Barcelona. Consorci d'Educació de Barcelona.

Boterman, W. R. (2013). Dealing with diversity: Middle-class family households and the issue of "black" and "white" schools in Amsterdam. Urban Studies, 5O(6), 1130-1147. https://doi.org/10.1177/0042098012461673

Boterman, W., Musterd, S., Pacchi, C. y Ranci, C. (2019). School segregation in contemporary cities: Socio-spatial dynamics, institutional context and urban outcomes. Urban Studies, 56(15), 3055-3073. https://doi.org/10.1177/0042098019868377

Brandén, M. y Bygren, M. (2018). School choice and school segregation: Lessons from Sweden's school voucher system. The Institute for Analytical Sociology.

Burgess, S., McConnell, B., Propper, C. y Wilson, D. (2007). The impact of school choice on sorting by ability and socioeconomic factors in English secondary education. En L. Woessmann y P. Peterson (Eds.), Schools and the equal opportunity problem (pp. 273-292). MIT Press.

Butler, T. y Robson, G. (2003). Plotting the middle classes: Gentrification and circuits of education in London. Housing Studies, 18(1), 5-28. https://doi.org/10.1080/0267303032000076812

Chubb, J. E. y Moe, T. (1990). Politics, markets Eீ America's schools. The Brookings Institution.

Cobb, C. D. y Glass, G. V. (2003). Arizona charter schools: Resegregating public education? AERA.

Dupriez, V., Barbana S. y Verhoven, M. (2018). Structural and systemic dimensions of school segregation in French-speaking Belgium. En X. Bonal y C. Bellei (Eds.), Understanding school segregation: Patterns, causes and consequences of spatial inequalities in education (pp. 45-64). Bloomsbury Academic.

Elacqua, G. (2012). The impact of school choice and public policy on segregation: Evidence from Chile. International Journal of Educational Development, 32(3), 444-453. https://doi.org/10.1016/j.ijedudev.2011.08.003

Elacqua, G., Montt, P. y Santos, H. (2013). Evidencias para eliminar gradualmente el financiamiento compartido. Instituto de Políticas Públicas.

Felouzis, G., Maroy, C. y van Zanten, A. (2013). Les marchés scolaires: Sociologie d'une politique publique d'éducation. Presses Universitaires de France. https://doi.org/10.3917/puf.felou.2013.01

Frankenberg, E., Siegel-Hawley, G. y Wang, J. (2011). Choice without equity: Charter school segregation. Educational Policy Analysis Archives, 19(1), 1-96.

https://doi.org/10.14507/epaa.v19n1.2011 
Garcia, D. R. (2008). The impact of school choice on racial segregation in charter schools. Educational Policy, 22(6), 805-829. https://doi.org/10.1177/0895904807310043

Gewirtz, S., Ball, S. J. y Bowe, R. (1995). Markets, choice, and equity in education. Open University Press.

Gorard, S. y Siddiqui, N. (2016). Grammar schools in England: A new approach to analyzing their intakes and outcomes. Durham University Press.

Hoxby, C. M. (1998). What do america's 'traditional' forms of school choice teach us about school choice reforms? Economic Policy Review, 4(1), 47-59.

Hoxby, C. M. (2003). The economics of school choice. University of Chicago Press. https://doi.org/10.7208/chicago/9780226355344.001.0001

Hsieh, C. T. y Urquiola, M. (2006). The effects of generalized school choice on achievement and stratification: Evidence from Chile's voucher program. Journal of Public Economics, 90(9), 1477-1503. https://doi.org/10.1016/j.jpubeco.2005.11.002

Kye, S. H. (2018). The persistence of white flight in middle-class suburbia. Social Science Research, 72, 38-52. https://doi.org/10.1016/j.ssresearch.2018.02.005

Lindbom, A. (2010). School choice in Sweden: Effects on student performance, school costs, and segregation. Scandinavian Journal of Educational Research, 54(6), 615-630. https://doi.org/10.1080/00313831.2010.522849

Merrifield, J. (2001). The school choice wars. Rowman \& Littlefield.

Musset, P. (2012). School choice and equity: Current policies in OECD countries and literature review. OECD Education Working Papers, 66, 1-51.

OECD. (2017). School choice and school vouchers: An OECD perspective. OECD Publishing.

OECD. (2019). Balancing school choice and equity: An international perspective based on PISA. OECD Publishing. https://doi.org/10.1787/2592c974-en

Östh, J., Andersson, E. y Malmberg, B. (2013). School choice and increasing performance difference: A counterfactual approach. Urban Studies, 50(2), 407-425.

https://doi.org/10.1177/0042098012452322

Riedel, A., Schneider, K., Schneider, C. y Weishaupt, H. (2010). School choice in German primary schools: How binding are school districts? Journal for Educational Research Online, 2(1), 94120.

Santos, H. y Elacqua, G. (2016). Segregación socioeconómica escolar en Chile: Elección de la escuela por los padres y un análisis contrafactual teórico. CEPAL Review, 119, 133-148. https://doi.org/10.18356/bd46ae92-es

Saporito, S. y Sohoni, D. (2006). Coloring outside the lines: Racial segregation in public schools and their attendance boundaries. Sociology of Education, 79, 81-105. https://doi.org/10.1177/003804070607900201

Síndic de Greuges. (2016). La segregació escolar a Catalunya (I): La gestió del procés d'admissió de l'alumnat. Síndic de Greuges de Catalunya.

Söderström, M. y Uusitalo, R. (2010). School choice and segregation: Evidence from an admission reform. Scandinavian Journal of Economics, 112(1), 55-76. https://doi.org/10.1111/j.1467-9442.2009.01594.x

Taylor, C. (2001). The geography of choice and diversity in the 'new' secondary education market in England. Area, 33(4), 368-381. https://doi.org/10.1111/1475-4762.00043 
van Zanten, A. (1996). Fabrication et effets de la ségrégation scolaire. En S. Paugam (Ed.), L'exclusion, l'état des savoirs (pp. 281-291). La Découverte.

Waslander, S., Pater, C. y van der Weide, M. (2010). Markets in education: An analytical review of empirical research on market mechanisms in education. OECD Education Working Paper Series, 52, 93-96.

West, A., Hind, A. y Pennell, H. (2004). School admissions and selection in comprehensive schools: Policy and practice. Oxford Review of Education, 30(3), 347-369. https://doi.org/10.1080/0305498042000260485

\section{Breve CV de los autores}

\section{Xavier Bonal}

Catedrático de Sociología en la Universidad Autónoma de Barcelona, Special Professor of Education and International Development en la Universidad de Amsterdam, director del centro Globalización, Educación y Políticas Sociales (GEPS) y coordinador del Máster Erasmus Mundus GLOBED: Education Policies for Global Development. Ha sido miembro fundador de la Red Europea sobre Globalización y Educación (GENIE) y miembro de la red de expertos en ciencias sociales y educación (NESSE) de la Comisión Europea. Ha realizado investigaciones en el ámbito de la sociología de la educación y la política educativa en España, Europa y América Latina. Ha sido consultor para diversos organismos internacionales, como UNICEF, UNESCO, el Consejo de Europa o la Dirección General de Educación de la Comisión Europea y profesor invitado en diversas universidades europeas y latinoamericanas. Cuenta con numerosas publicaciones en revistas nacionales e internacionales $y$ es autor de varios libros. ORCID ID: https://orcid.org/O000-0003-0625-0951. Email: xavier.bonal@uab.cat

\section{Adrián Zancajo}

Doctor en sociología por la Universidad Autónoma de Barcelona y actualmente British Academy postdoctoral fellow en la Facultad de Educación de la Universidad de Glasgow. Actualmente, desarrolla un proyecto de investigación sobre la regulación de los mercados educativos, con especial énfasis en el caso de Chile. Sus líneas de investigación incluyen el estudio de las políticas de privatización, las reformas promercado, la segregación escolar y las desigualdades educativas. Ha participado en diversos proyectos de investigación entre ellos "Public-Private Partnerships in Educational Governance: An analysis of its dissemination, implementation and impact in a globalizing world" y "Los nuevos cuasimercados en educación en América Latina. Un análisis de su implementación e impacto sobre la desigualdad educativa y la pobreza”. También ha desarrollado investigaciones para organizaciones como Education International, Open Society Foundation, Fundació Jaume Bofill, Observatori català de la joventut e Institut infància i adolescencia. ORCID ID: https://orcid.org/oOOO-0002-4431-8155. Email: adrian.zancajo@glasgow.ac.uk 